\title{
Validation of aerosol and cloud layer structures from the space-borne lidar CALIOP using a ground-based lidar in Seoul, Korea
}

\author{
S.-W. Kim ${ }^{1,2}$, S. Berthier ${ }^{1}$, J.-C. Raut ${ }^{1}$, P. Chazette ${ }^{1}$, F. Dulac ${ }^{1}$, and S.-C. Yoon ${ }^{2}$ \\ ${ }^{1}$ Laboratoire des Sciences du Climat et de l'Environnement, CEA-CNRS-UVSQ, Gif-Sur-Yvette, France \\ ${ }^{2}$ School of Earth and Environmental Sciences, Seoul National University, Seoul, South Korea
}

Received: 10 July 2007 - Published in Atmos. Chem. Phys. Discuss.: 1 August 2007

Revised: 4 April 2008 - Accepted: 2 May 2008 - Published: 11 July 2008

\begin{abstract}
We present initial validation results of the space-borne lidar CALIOP onboard CALIPSO satellite using coincidental observations from a ground-based lidar in Seoul National University (SNU), Seoul, Korea $\left(37.46^{\circ}\right.$ N, $\left.126.95^{\circ} \mathrm{E}\right)$. We analyze six selected cases between September 2006 and February 2007, including 3 daytime and 3 night-time observations and covering different types of clear and cloudy atmospheric conditions. Apparent scattering ratios calculated from the two lidar measurements of total attenuated backscatter at $532 \mathrm{~nm}$ show similar aerosol and cloud layer structures both under cloud-free conditions and in cases of multiple aerosol layers underlying semitransparent cirrus clouds. Agreement on top and base heights of cloud and aerosol layers is generally within $0.10 \mathrm{~km}$, particularly during night-time. This result confirms that the CALIPSO science team algorithms for the discrimination of cloud and aerosol as well as for the detection of layer top and base altitude provide reliable information in such atmospheric conditions. This accuracy of the planetary boundary layer top height under cirrus cloud appears, however, limited during daytime. Under thick cloud conditions, however, information on the cloud top (bottom) height only is reliable from CALIOP (ground-based lidar) due to strong signal attenuations. However, simultaneous space-borne CALIOP and ground-based SNU lidar (SNUL) measurements complement each other and can be combined to provide full information on the vertical distribution of aerosols and clouds. An aerosol backscatter-to-extinction ratio (BER) estimated from lidar and sunphotometer synergy at the SNU site during the CALIOP overpass is assessed to be $0.023 \pm 0.004 \mathrm{sr}^{-1}$ (i.e. a lidar ratio of $43.2 \pm 6.2 \mathrm{sr}$ ) from
\end{abstract}

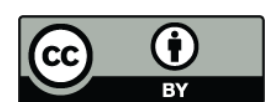

Correspondence to: S.-W. Kim (sang-woo.kim@cea.fr)
CALIOP and $0.027 \pm 0.006 \mathrm{sr}^{-1}$ (37.4 $\pm 7.2 \mathrm{sr}$ ) from SNUL. For aerosols within the planetary boundary layer under cloud-free conditions, the aerosol extinction profiles from both lidars are in agreement within about $0.02 \mathrm{~km}^{-1}$. Under semi-transparent cirrus clouds, such profiles also show good agreement for the night-time CALIOP flight, but large discrepancies are found for the daytime flights due to a small signal-to-noise ratio of the CALIOP data.

\section{Introduction}

Space-borne active remote sensing (e.g. LITE (Lidar Inspace Technology Experiment; McCormick et al., 1993), GLAS (Geoscience Laser Altimeter System; Spinhirne et al., 2005) and CALIPSO (Cloud-Aerosol Lidar and Infrared Pathfinder Satellite Observations; Winker et al., 2004, 2006, 2007)) of atmospheric aerosols and clouds is the key to providing global vertically resolved observations that are needed to better understand a variety of aerosol-cloudradiation-climate feedback processes (e.g. Spinhirne et al., 2005; Berthier et al., 2006). Contrary to the previously launched passive sensors, especially, the recently-launched space-based backscatter lidar Cloud-Aerosol Lidar with Orthogonal Polarization (CALIOP) onboard CALIPSO provides information on the vertical distribution of aerosols and clouds as well as on their optical and physical properties over the globe with unprecedented spatial resolution (Winker et al., 2006, 2007). Validation of CALIOP products via intercomparison with independent measurements is essential to the production of a high quality dataset (Liu et al., 2006; Winker et al., 2006). An important early activity for CALIOP is thus to link its measurements with those from ground-based or airborne measurements along the tracks for

Published by Copernicus Publications on behalf of the European Geosciences Union. 
validation of data and derived science products and for further synergetic studies (e.g. input/validation of global-scale modeling). McGill et al. (2007) present initial airborne validation results where cloud layer top determinations from CALIPSO are found to be in good agreement with those from the Cloud Physics Lidar (CPL) onboard NASA ER-2 research aircraft. The minimum detectable backscatter levels are also in excellent agreement with those predicted prior to the CALIPSO launch.

This study presents initial validation results of space-borne lidar CALIOP profiles by comparing space and time coincidental measurements collected by a ground-based lidar at Seoul National University (SNU; $37.4579^{\circ} \mathrm{N}, 126.9520^{\circ} \mathrm{E}$, 116 m a.m.s.l), Seoul, South Korea, hereafter denoted SNUL. We perform direct profile-to-profile comparisons of the apparent scattering ratio, which is calculated from the coincident measurement datasets of the total $532 \mathrm{~nm}$ attenuated backscatter signal (i.e. the sum of the $532 \mathrm{~nm}$ parallel and perpendicular return signals) from both space-based CALIOP and ground-based SNU-L. We also compare the CALIOP level-2 products of height and thickness of aerosol and cloud layers. This validation is made for 3 different types of atmospheric scenes: (1) boundary aerosol layer under cloud-free conditions, (2) multiple aerosol layers underlying semi-transparent cirrus clouds, and (3) aerosol layer under thick tropospheric clouds. A comparison of aerosol extinction profile between CALIOP and SNU-L measurements both under cloud-free conditions and in cases of multiple aerosol layers underlying semi-transparent cirrus clouds is also presented. We further derive the backscattering-toextinction ratio (BER) for boundary layer aerosols under clear conditions from both lidars.

\section{Overview of the lidar measurements and the valida- tion approach}

For the CALIPSO mission, validation is defined as an assessment of the accuracy and precision of the derived science products by independent airborne or ground-based measurements (Kovacs and McCormick, 2006). Although a large number of ground-based lidar systems could potentially be involved in CALIOP validation efforts (e.g. MPL-NET, EARLINET, AD-NET), coincidence opportunities for direct comparisons between CALIOP observations and groundbased lidars are not as straight forward. Spatial and temporal variability of aerosol and cloud constraint greatly complicate the validation of CALIOP products by direct comparison with instruments at ground stations. Especially, clouds have relatively short lifetimes and even shorter correlation spatial scales (a few hundred meters to tens of kilometers). Indeed, CALIOP has a very narrow swath and carries out measurements over a significant horizontal distance during a short period of time, while ground-based lidar (e.g. SNU$\mathrm{L}$ used in this study) with a narrow field-of-view is local- ized, changes in the profile being only due to atmospheric motions. Moreover CALIPSO has not a global coverage in a day and flies over a given site every 16 days only (1 daytime plus 1 night-time pass). On the other hand, up-looking versus down-looking viewing geometries also play a big role, as do calibration procedures. Signal attenuation by atmospheric constituents such as air molecules, aerosols and clouds need to be explicitly taken into account.

\subsection{Space-borne lidar CALIOP onboard CALIPSO}

The payload on the CALIPSO satellite is composed of a lidar system denoted CALIOP, a 3-channel imaging infrared radiometer and a wide field camera. We focus here on CALIOP, a nadir-pointing instrument which is built around a diode-pumped Nd:YAG laser. While the CALIOP transmitter emits polarized light at both 1064 and $532 \mathrm{~nm}$ with a pulse energy of $110 \mathrm{~mJ}$ and a pulse repetition rate of $20.25 \mathrm{~Hz}$, polarization discrimination in the receiver is only done for the $532 \mathrm{~nm}$ channel (Winker et al., 2004, 2007). CALIOP is calibrated by normalizing the return signal between 30 and $34 \mathrm{~km}$ above mean sea level (a.m.s.l.) (Hostetler et al., 2005). Details on the instrument, data acquisition, and science products are given in Anselmo et al. (2006) and Winker et al. (2007). Here we use CALIOP level-1 (version 1.10 (13 June 2006 5 January 2007) and 1.11 (6 January 2007 13 March 2007)) and -2 data (version 1.10). CALIOP level-1 data have different spatial resolutions for different altitude ranges: $30 \mathrm{~m}(60 \mathrm{~m}$ at $1064 \mathrm{~nm})$ vertically and $333 \mathrm{~m}$ horizontally between -0.5 and $8.2 \mathrm{~km}$ (a.m.s.l.); $60 \mathrm{~m}$ vertically and $1000 \mathrm{~m}$ horizontally between 8.2 and $20.2 \mathrm{~km}$ a.m.s.l. The CALIOP level-2 aerosol and cloud layer products (i.e., the vertical location of aerosol and cloud layer boundaries; Vaughan et al., 2005) are produced at a $5-\mathrm{km}$ horizontal resolution for aerosols, and at three horizontal resolutions for clouds: $0.333 \mathrm{~km}$ (full resolution, but limited up to $8.2 \mathrm{~km}$ a.m.s.1.), $1 \mathrm{~km}$ (medium resolution available below $20.2 \mathrm{~km}$ amsl), and $5 \mathrm{~km}$ (low resolution available for the full column). Cloud/aerosol discrimination in CALIPSO level2 algorithms is performed using an adaptive threshold on the magnitude and spectral variation of the lidar backscatter at both wavelengths (Liu et al., 2004; Vaughan et al., 2004). The CALIOP observation period considered here extends from the beginning of CALIOP measurements in June 2006 to April 2007.

\subsection{Ground-based 2-wavelength polarization lidar in Seoul, Korea}

The ground-based SNU lidar (SNU-L) has also the same two wavelengths as CALIOP (1064 and $532 \mathrm{~nm}$ ) with the depolarization ratio measurement at $532 \mathrm{~nm}$ (Kim et al., 2006; Shimizu et al., 2004; Sugimoto et al., 2002, 2005, 2006). It was developed by the Japanese National Institute for Environmental Studies (NIES) and has been operated as part 
Table 1. Summary of aerosol and cloud conditions and retrieved aerosol parameters for the selected cases.

\begin{tabular}{|c|c|c|c|c|c|c|}
\hline & \multirow{2}{*}{$\begin{array}{c}\text { Case } 1 \\
24 \text { Oct } 2006 \\
\text { (daytime) }\end{array}$} & \multicolumn{3}{|c|}{ Case 2} & \multicolumn{2}{|c|}{ Case 3} \\
\hline & & $\begin{array}{l}25 \text { Nov } 2006 \\
\text { (daytime) }\end{array}$ & $\begin{array}{l}21 \text { Feb } 2007 \\
\text { (night-time) }\end{array}$ & $\begin{array}{c}12 \text { Jan } 2007 \\
\text { (daytime) }\end{array}$ & $\begin{array}{l}14 \text { Sep } 2006 \\
\text { (night-time) }\end{array}$ & $\begin{array}{l}30 \text { Sep } 2006 \\
\text { (night-time) }\end{array}$ \\
\hline \multicolumn{7}{|l|}{ (a) Aerosol and Cloud Conditions } \\
\hline Aerosols in PBL & $\sqrt{ }$ & $\sqrt{ }$ & $\sqrt{ }$ & $\sqrt{ }$ & $\sqrt{ }$ & $\sqrt{ }$ \\
\hline Semi-transparent Cirrus & - & $\sqrt{ }$ & $\sqrt{ }$ & $\sqrt{ }$ & - & - \\
\hline Dense Tropospheric Clouds & - & - & - & - & $\sqrt{ }$ & $\sqrt{ }$ \\
\hline \multicolumn{7}{|l|}{ (b) Retrieved Parameters } \\
\hline Apparent Scattering Ratio ( $\left.Z_{\text {ref-below }}\right)$ & $\sqrt{ }$ & $\sqrt{ }$ & $\sqrt{ }$ & $\sqrt{ }$ & - & - \\
\hline Apparent Scattering Ratio ( $\left.Z_{\text {ref-above }}\right)$ & $\sqrt{ }$ & $\sqrt{ }$ & $\sqrt{ }$ & $\sqrt{ }$ & $\sqrt{ }$ & $\sqrt{ }$ \\
\hline Aerosol Extinction Coefficient & $\sqrt{ }$ & $\sqrt{ }$ & $\sqrt{ }$ & $\sqrt{ }$ & - & - \\
\hline
\end{tabular}

of the Japanese NIES lidar network (http://www-lidar.nies. go.jp; Sugimoto et al., 2006) as well as the Asian dust network (AD-Net; http://www-lidar.nies.go.jp/AD-Net/index. html; Murayama et al., 2001). SNU-L employs a Nd:YAG laser (pulse energy of $20 \mathrm{~mJ}$; pulse repetition rate of $10 \mathrm{~Hz}$ ) and an analog detection system. This instrument is identical to the lidar hardware systems distributed in the NIES lidar network, and the same instrument calibration and data retrieval process have been applied. Detailed information on the calibration method and its accuracy can be found in Shimizu et al. (2004). SNU-L makes the vertical profile from surface to $18 \mathrm{~km}$ every $15 \mathrm{~min}$ (starting at 00, 15, 30, $45 \mathrm{~min}$ of every hour) with a 6-m vertical resolution. The measurement sequence of SNU-L is such that it runs 5 min (i.e., total 3000 shots) and then stops during the next $10 \mathrm{~min}$. The background noise is estimated by an average of the uppermost 100 data points $(17.4 \sim 18 \mathrm{~km}$ a.m.s.l.) for each single-shot measurement. The aerosol vertical profiles obtained from the SNU 2-wavelength polarization lidar system were well compared with those from co-located micro-pulse lidar at Gosan, Korea, during the Atmospheric Brown Cloud (ABC)East Asian Regional Experiment 2005 (EAREX, 2005, see http://abc-gosan.snu.ac.kr). The aerosol extinction profiles were in agreement within $0.0051 \mathrm{~km}^{-1}$ bias (Kim et al., 2006). The SNU-L aerosol and cloud layer identification method is based on detecting the maximum gradient in the returned lidar backscattering intensity and was successfully applied for estimating the urban aerosol mixing height (Kim et al., 2007).

Current and past quick-look images of SNU-L can be found at the NIES lidar network web site (http://www-lidar. nies.go.jp/Seoul/index.html). The SNU lidar is well located to study locally emitted urban aerosols, long-range transported aerosols from continental Asia, and clouds. Moreover, some CALIPSO ground tracks are fortunately located within $10 \mathrm{~km}$ (approximately $0.1^{\circ}$ ) from the SNU ground-based lidar station. This meets the CALIPSO validation guidelines for aerosol and clouds (Kovacs et al., 2004; Kovacs and McCormick, 2005; Kovacs, 2006). However, approximately $70 \%$ of SNU lidar data are unavailable for comparison due to unfavorable weather conditions (e.g. precipitation, thick cloud in planetary boundary layer, and dense fog).

\subsection{Sampled atmospheric situations and validation ap- proach}

Over the considered period, 6 favorable cases were selected for CALIOP validation, including 3 daytime and 3 night-time cases, and 3 different types of atmospheric aerosol and cloud scenes (Table 1): (case 1) 1 scene of PBL aerosols under clear sky condition, (case 2) 3 scenes of multiple aerosol layers underlying semi-transparent cirrus clouds, and (case 3) 2 scenes of dense clouds. Figure 1 presents the location of SNU-L and CALIPSO ground tracks for the 6 selected cases.

To avoid huge sampling volume discrepancies due to different vertical resolution and horizontal footprint size of data between the two instruments, we averaged the closest 18 profiles of CALIOP, as shown in Fig. 1 with closed circles along the tracks. This corresponds to a sampling duration of $\sim 0.9 \mathrm{~s}$ and an horizontal coverage of $\sim 6.0 \mathrm{~km}$. CALIPSO flies over the SNU-L site at 04:50 UTC (13:50 local time) during daytime (ascending) and 17:41 UTC (02:41 local time) during night-time (descending). The 5-min averaged SNUL profiles, comprising 3000 shots, acquired between 04:45 and 04:50 UTC (daytime) or between 17:45 and 17:50 UTC (night-time) are used for comparison.

We consider both level-1 (532 nm channel only) and level2 data to compare the aerosol and cloud layer structures respectively derived from CALIOP and SNU-L. For level1 , we calculate apparent scattering ratio profiles $R_{\text {app }}(z)$ to remove the different transmission effects of air molecules between the nadir-viewing space-borne CALIOP and the zenith-viewing ground-based SNU-L $\left(R_{\text {app }}(z)=1\right.$ in case of a molecular atmosphere; see Sect. 3.1). The level-2 CALIOP products on aerosol ( $5 \mathrm{~km}$ horizontal resolution) and cloud 


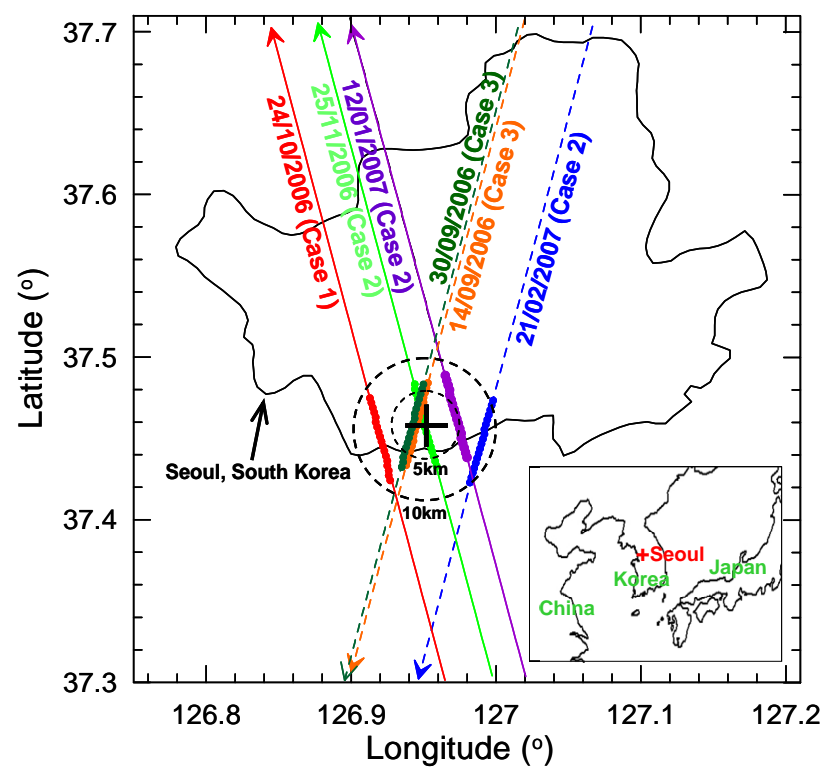

Fig. 1. Location of the ground-based lidar monitoring station at Seoul National University (SNU, crosshair), Seoul, South Korea and CALIPSO orbit ground tracks for the 6 days used in this study. The solid and dashed lines represent daytime ascending and nighttime descending nodes of CALIPSO orbit, respectively. The 18 CALIOP-derived profiles closest to the SNU site, which are acquired at 04:50 UTC (13:50 local time) and 17:41 UTC (02:41 local time), have been selected for comparison (closed circles along the tracks). The inner $(5 \mathrm{~km})$ and outer $(10 \mathrm{~km})$ dashed circles represent the horizontal distance from the ground-based SNU lidar site.

( $1 \mathrm{~km}$ horizontal resolution) layer top and bottom were compared with those from SNU-L. Note that we average the 6 profiles of level-2 CALIOP cloud top and bottom height products at $1 \mathrm{~km}$ horizontal resolution, because these 6 profiles cover $6 \mathrm{~km}$ along the CALIPSO ground track, which is almost identical to the horizontal coverage of the 18 profiles of level-1 CALIOP data. Finally, CALIOP and SNU$\mathrm{L}$ aerosol extinction profiles are also compared both under cloud-free conditions and in cases of multiple aerosol layers underlying semi-transparent cirrus clouds.

\section{Methods for lidar signal retrievals}

\subsection{Apparent scattering ratio}

We calculate the apparent scattering ratio $R_{\text {app }}(z)$ as:

$R_{\mathrm{app}}(z)=\frac{S_{2}(z)}{S_{2}\left(z_{\text {ref }}\right)} \frac{\beta_{\mathrm{mol}}\left(z_{\mathrm{ref}}\right)}{\beta_{\mathrm{mol}}(z)} \exp \left(2 \int_{z_{\mathrm{ref}}}^{z} \alpha_{\mathrm{mol}} d z\right)$

where $S_{2}(z)$ and $S_{2}\left(z_{\text {ref }}\right)$ are the range-corrected and background noise-subtracted lidar return signals, respectively at the altitude $z$ and at a reference altitude $z_{\text {ref }}$ corresponding to a Rayleigh scattering regime $\left[R_{\text {app }}\left(z_{\text {ref }}\right)=1\right]$. It is worth to mentioning that the magnitude of $R_{\text {app }}(z)$ depends on $z_{\text {ref. }}$ For example, choosing $z_{\text {ref }}$ beneath the cirrus layers for CALIOP will cause $R_{\text {app }}(z)$ to overestimate the true scattering ratio. In this study, $z_{\text {ref }}$ is taken between 10 and $11 \mathrm{~km}$ ( $z_{\text {ref }}$ above) and 5 and $6 \mathrm{~km}$ ( $\left.z_{\text {ref-below }}\right)$ for boundary aerosol layer under cloud-free conditions (see Sect. 4.1) as well as between 12 and $13 \mathrm{~km}$ (above cirrus; $z_{\text {ref_above) }}$ and 5 and $6 \mathrm{~km}$ (below cirrus; $z_{\text {ref_below) for }}$ multiple aerosol layers underlying semi-transparent cirrus clouds (see Sect. 4.2). However, $z_{\text {ref }}$ is only taken between 12 and $13 \mathrm{~km}$ ( $z_{\text {ref }}$ above) for aerosol layers under thick tropospheric clouds (see Sect. 4.3). The CALIOP signal appears to be completely attenuated beneath dense cloud layer (e.g. no evidence of a surface return, see Figs. 6 and 8), so the data under dense cloud layer is either noise or detector artifact (Winker et al., 2007). $\beta_{\mathrm{mol}}$ and $\alpha_{\mathrm{mol}}$ are molecular backscattering and extinction coefficients, respectively. $S_{2}(z)$ is given by the basic lidar equation:

$S_{2}(z)=C \cdot \beta(z) \cdot \exp \left(-2 \int_{0}^{z}\left[\alpha_{\mathrm{mol}}\left(z^{\prime}\right)+\alpha_{\mathrm{aer}}\left(z^{\prime}\right)\right] d z^{\prime}\right)$

where $C$ is a system constant, $\beta$ is total backscattering coefficient, and $\alpha_{\text {aer }}$ is aerosol or cloud particle extinction coefficient. By definition of $S_{2}(z)$ and $S_{2}\left(z_{\text {ref }}\right)$, we can rewrite Eq. (1) as follows:

$R_{\text {app }}(z)=R_{\text {real }}(z) \exp \left(-2 \int_{z_{\text {ref }}}^{z} \alpha_{\text {aer }}\left(z^{\prime}\right) d z^{\prime}\right)$

where the real scattering ratio $R_{\text {real }}(z)$ is $\frac{\beta(z)}{\beta_{\text {mol }}(z)}$. Compared to $R_{\text {real }}(z), R_{\text {app }}(z)$ is only affected by atmospheric aerosol and cloud particles. We calculate the corresponding uncertainty using the variance (Var) on the retrieved profile of apparent scattering ratio. It is computed as follows:

$\operatorname{Var}\left[R_{\text {app }}(z)\right]=\left[\frac{\beta_{\text {mol }}\left(z_{\text {ref }}\right)}{\beta_{\text {mol }}(z)} \exp \left(-2 \int_{z_{\text {ref }}}^{z} \alpha_{\text {mol }}\left(z^{\prime}\right) d z^{\prime}\right)\right]^{2}$
$\times\left[\left(\frac{1}{S_{2}\left(z_{\text {ref }}\right)}\right)^{2} \operatorname{Var}\left(S_{2}(z)\right)+\left(\frac{S_{2}(z)}{S_{2}\left(z_{\text {ref }}\right)^{2}}\right)^{2} \operatorname{Var}\left[S_{2}\left(z_{\text {ref }}\right)\right]\right.$

with the assumption that $S_{2}(z)$ and $S_{2}\left(z_{\text {ref }}\right)$ are independent.

\subsection{Lidar ratio and aerosol extinction coefficient}

Four vertical profiles of aerosol extinction coefficient at $532 \mathrm{~nm}$ are retrieved from the Klett method (Klett, 1981, 1985): 1 for the single case of boundary aerosol layer under cloud-free conditions (case 1), as well as 3 for aerosols under semi-transparent cirrus clouds conditions (case 2). To solve the ill-posed problem of the lidar equation and extract the 
Table 2. Summary of aerosol and cloud layer identification.

\begin{tabular}{|c|c|c|c|c|}
\hline \multirow[t]{2}{*}{ Date } & \multirow[t]{2}{*}{ Aerosol and cloud layer label } & \multirow[t]{2}{*}{ Lidar } & \multicolumn{2}{|c|}{ Layer Height $(\mathrm{km})$} \\
\hline & & & Top & Bottom \\
\hline \multicolumn{5}{|c|}{ Case 1: PBL aerosols under clear sky } \\
\hline \multirow[t]{2}{*}{24 Oct 2006 (daytime) } & A (Fig. 2) & CALIOP & 1.20 & Ground \\
\hline & & SNU-L & 1.20 & Ground \\
\hline \multicolumn{5}{|c|}{ Case 2: Aerosols under thin cirrus } \\
\hline \multirow[t]{4}{*}{25 Nov 2006 (daytime) } & C (Fig. 3) & CALIOP & 11.45 & 10.87 \\
\hline & & SNU-L & 11.50 & 10.76 \\
\hline & A (Fig. 3) & CALIOP & 1.28 & Ground \\
\hline & & SNU-L & 1.29 & Ground \\
\hline \multirow[t]{8}{*}{21 Feb 2007 (night-time) } & C (Fig. 4) & CALIOP & 10.54 & 9.64 \\
\hline & & SNU-L & 10.45 & 9.60 \\
\hline & A3 (Fig. 4) & CALIOP & 3.63 & 3.42 \\
\hline & & SNU-L & 3.60 & 3.20 \\
\hline & A2 (Fig. 4) & CALIOP & 2.37 & 1.33 \\
\hline & & SNU-L & 2.40 & 1.30 \\
\hline & A1 (Fig. 4) & CALIOP & 1.02 & Ground \\
\hline & & SNU-L & 0.97 & Ground \\
\hline \multirow[t]{4}{*}{12 Jan 2007(daytime) } & C (Fig. 5) & CALIOP & 8.06 & 7.22 \\
\hline & & SNU-L & 8.00 & 7.19 \\
\hline & A (Fig. 5) & CALIOP & 0.78 & Ground \\
\hline & & SNU-L & 1.26 & Ground \\
\hline \multicolumn{5}{|c|}{ Case 3: Dense tropospheric clouds } \\
\hline \multirow[t]{4}{*}{ 14 Sep 2006 (night-time) } & $C_{S}$ (Fig. 6) & CALIOP & 11.20 & 4.95 \\
\hline & $C_{g}$ & SNU-L & 6.90 & 4.70 \\
\hline & $A_{g}$ (Fig. 6) & CALIOP & - & Ground \\
\hline & & SNU-L & 2.8 & Ground \\
\hline \multirow[t]{5}{*}{30 Sep 2006 (night-time) } & $C_{s}^{1}$ (Fig. 8) & CALIOP & 8.98 & 8.56 \\
\hline & $C_{s}^{2}$ & CALIOP & 7.64 & 6.80 \\
\hline & $C_{g}$ & SNU-L & 6.10 & 4.90 \\
\hline & $A_{g}$ (Fig. 8) & CALIOP & - & Ground \\
\hline & & SNU-L & 2.20 & Ground \\
\hline
\end{tabular}

aerosol extinction coefficient, we need to know an altitudeindependent backscatter-to-extinction ratio (BER, inverse of the so-called "lidar ratio" $\delta$ ). Alternatively, the knowledge of the column aerosol optical thickness can be used to derive an average BER value (e.g. Berthier et al., 2006; Chazette, 2003). Here the sunphotometer-derived aerosol optical thickness $\left(\tau_{a}\right)$ at the SNU-L station was measured for the single case of boundary aerosol layer under cloud-free conditions (case 1) and is used for the lidar signal inversion in order to retrieve the value of BER on 24 October 2006. The value of $\tau_{a}$ at $532 \mathrm{~nm}$ is calculated by the Ångström relationship using measurements at 400, 500 and $675 \mathrm{~nm}$. The BER value obtained is applied hereafter to the aerosol layers of the 3 case-2 profiles, because sunphotometer data are not available on those days due to the presence of cirrus clouds.

\section{Results and discussion}

The results on the top and bottom heights of aerosol and cloud layers are summarized in Table 2. Detailed discussions on the various cases are following.

4.1 Case 1: planetary boundary layer (PBL) aerosols under clear sky

Figure $2 \mathrm{a}$ and $\mathrm{b}$ shows color coded time-height images of the daytime level-1 data at $532 \mathrm{~nm}$ acquired by CALIOP and SNU-L on 24 October 2006. Note that the differences in the CALIOP data near $8 \mathrm{~km}$ in altitude in Fig. $2 \mathrm{a}$ are due to the different vertical and horizontal resolutions of the CALIOP data below and above $8.2 \mathrm{~km}$ (see Sect. 2.1). The vertical white dashed lines in Fig. $2 \mathrm{a}$ and $\mathrm{b}$ indicate the point of the nearest coincidence between the SNU-L site and the CALIPSO flight, which occurred at 04:50 UTC (13:50 local time). No cloud is observed around the area (Fig. 2a) 

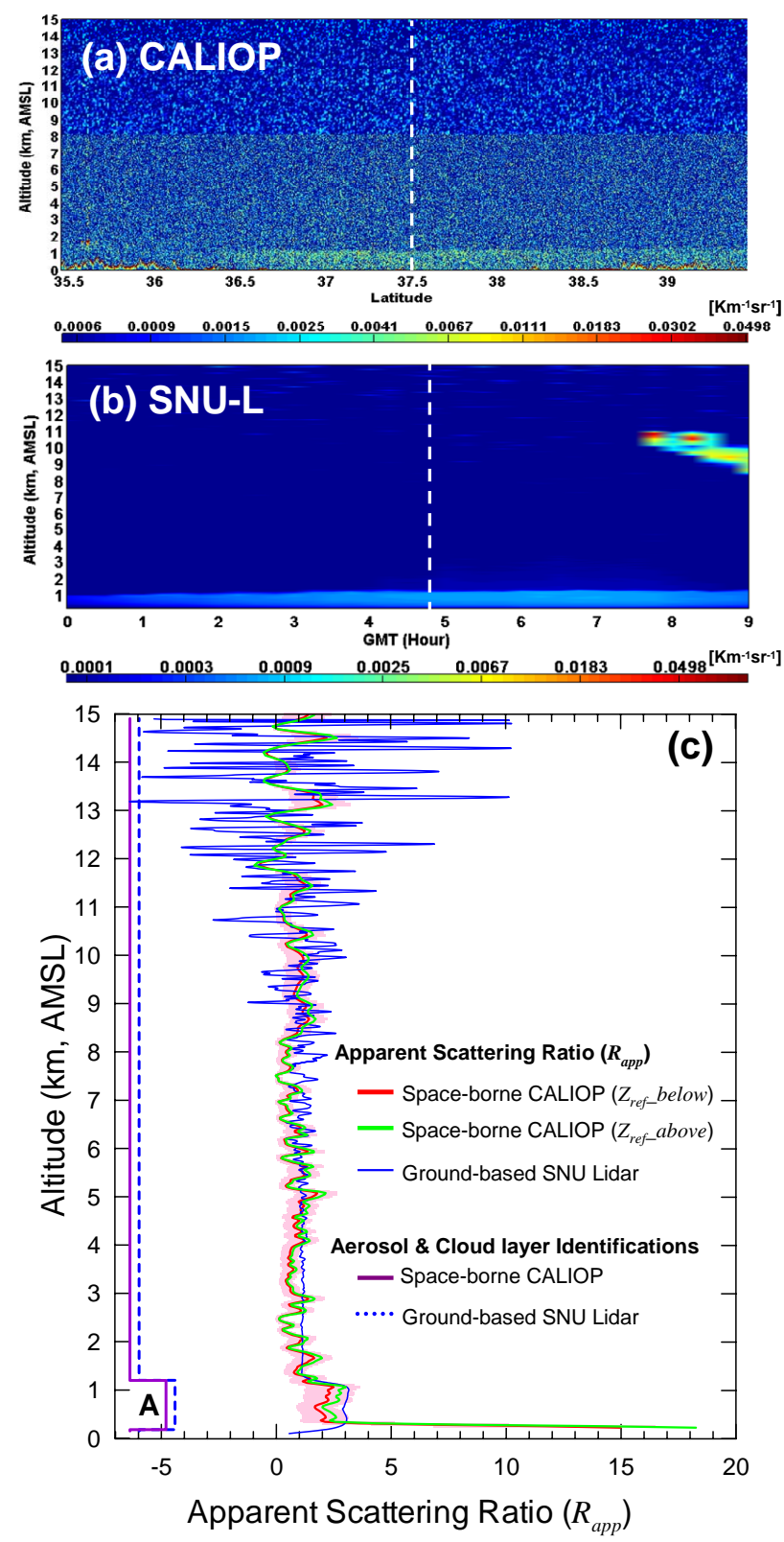

Fig. 2. Vertical profiles of (a) CALIOP-derived and (b) SNU lidar-derived total attenuated backscatter at $532 \mathrm{~nm}$ wavelength, and (c) apparent scattering ratios $R_{\text {app }}$ at $532 \mathrm{~nm}$ calculated from the CALIOP (04:50 UTC, red and green lines) and the SNU lidar (04:46 04:50 UTC, blue line) measurements on 24 October 2006. Two CALIOP $R_{\text {app }}$ profiles were obtained by choosing $z_{\text {ref }}$ between 10 and $11 \mathrm{~km}$ (green line;

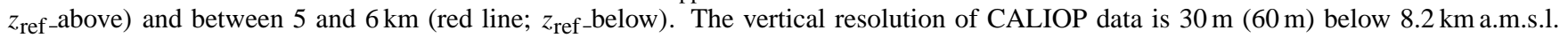
(above $8.2 \mathrm{~km}$ a.m.s.l.), whereas the SNU-L resolution is $6 \mathrm{~m}$ from surface up to $15 \mathrm{~km}$. The 5 -min SNU-L data taken every $15 \mathrm{~min}$ are interpolated. The vertical white dashed lines in (a) and (b) indicate the points of nearest spatial/temporal coincidence between the SNU lidar site and the CALIPSO flight. Because the plot is to be too complicated, the standard deviation (pink shaded envelope) of CALIOP $R_{\text {app }}\left(z_{\text {ref-below }}\right.$ is only represented in (c). The violet line and blue dashed line in (c) indicate the top and bottom heights of the aerosol layer, estimated by aerosol and cloud layer identification algorithm (level-2) of CALIPSO science team and SNU algorithm, respectively. The label "A" indicates an aerosol layer.

and time (Fig. 2b) of the coincidence. A horizontally stable boundary aerosol layer under cloud-free conditions is observed before and after the CALIPSO northward-flying over the SNU site. Similarly, ground-based SNU-L measurements show a temporally stable PBL aerosol layer below approximately $1.2 \mathrm{~km}$ amsl before and after the CALIPSO overpass.

Figure 2c compares the vertical profiles of the apparent scattering ratio $R_{\text {app }}$ at $532 \mathrm{~nm}$, as well as the level- 

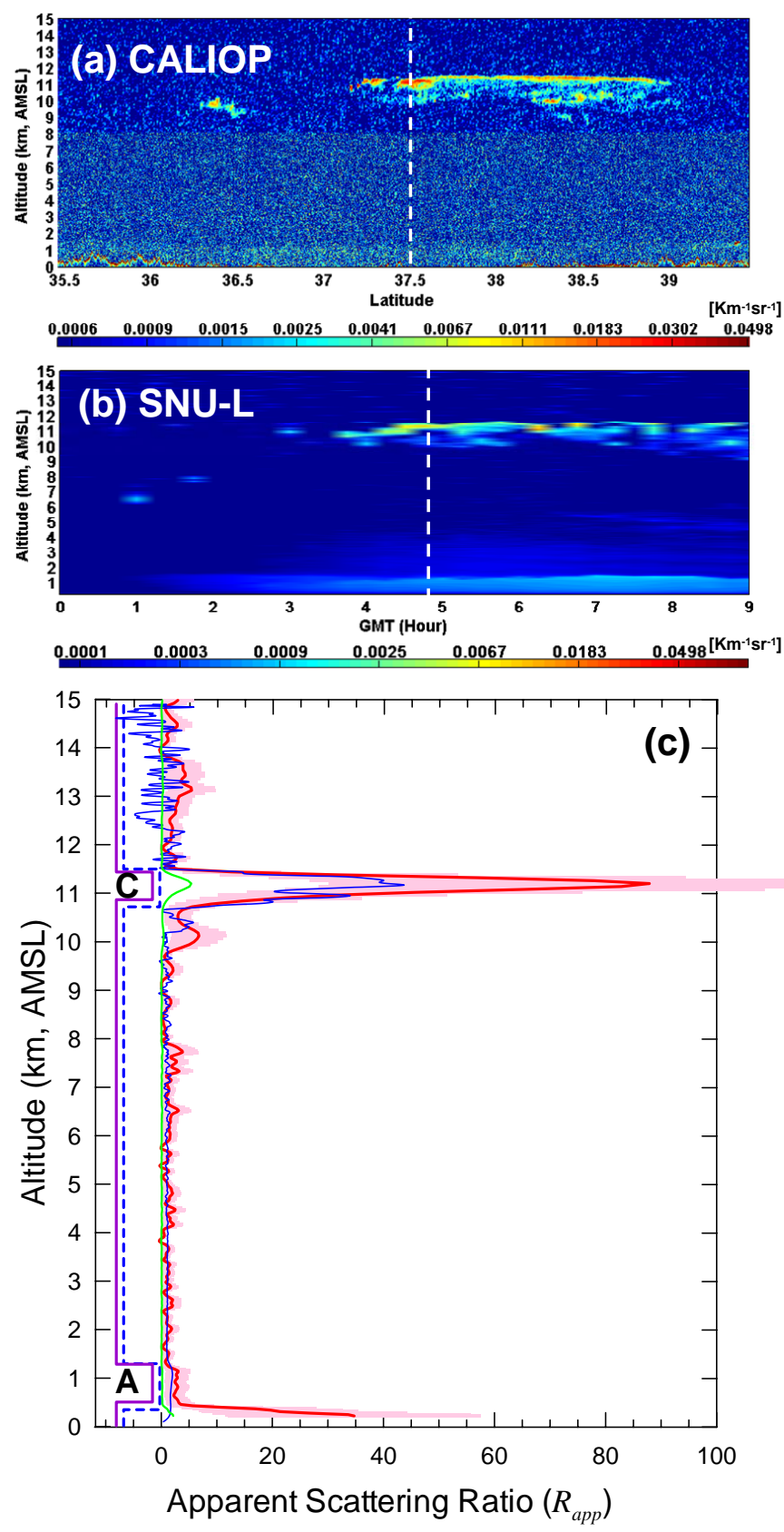

Fig. 3. Same as Fig. 2, except for the date (25 November 2006, 04:50 UTC) and the presence of additional transmissive high-altitude cirrus cloud (label "C") overlying the aerosol layer in the lower troposphere. $z_{\text {ref }}$ for CALIOP $R_{\text {app }}$ calculation is chosen between 12 and $13 \mathrm{~km}$

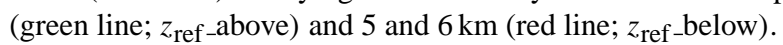

2 cloud/aerosol layer flag, as calculated at the coincident point. As we noted in Sect. 3.1, CALIOP $R_{\text {app }}$ profiles are calculated by choosing $z_{\text {ref }}$ between 10 and $11 \mathrm{~km}$

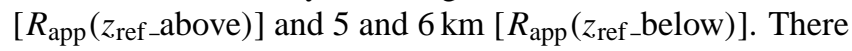
is no significant difference in choosing different $z_{\text {ref }}$ under cloud-free conditions. The boundary layer is more clear when $z_{\text {ref }}$ is taken in highest altitudes ( $z_{\text {ref }}$ above). In the absence of clouds, both lidars detect well typical urban PBL aerosols. $R_{\text {app }}$ of ground-based SNU-L for aerosol layer in PBL falls into the uncertainty range of CALIOP-derived $R_{\text {app }}$ ( $z_{\text {ref }}$ below) (pink area in Fig. 2c). Note that the peak of CALIOP-derived $R_{\text {app }}$ near the surface is attributable to high reflection from the ground due to slightly inhomogeneous surface elevation along CALIPSO ground tracks. On the opposite, the sharp decrease of the SNU-L derived $R_{\text {app }}$ near the surface is due to the loss of overlap between the laser beam 
and the telescope field of view. Although there is no multiple scattering problem in CALIOP signal in this case, relatively large variations of the CALIOP-derived $R_{\text {app }}$ above the boundary aerosol layer (i.e., between 1.3 and $8 \mathrm{~km}$ a.m.s.l.) are apparent compared to the $R_{\text {app }}$ profile from SNU-L. It is important to bear in mind that daytime CALIOP data is, of course, noisier than that of night-time (e.g. Fig. 4) due to contamination by solar background (e.g. McGill et al., 2007).

Meantime, the level-2 CALIOP aerosol/cloud layer height product (violet line in Fig. 2c) indicates the top height of the planetary boundary layer at $1.20 \mathrm{~km}$ a.m.s.l. (Table 2), which corresponds well with the SNU-L retrieval (blue dashed line in Fig. 2c; Table 2).

\subsection{Case 2: aerosols under thin cirrus}

In this section, we show comparisons of $R_{\text {app }}$ profiles on the conditions of aerosol layer(s) underlying the semitransparent cirrus clouds. Three $R_{\text {app }}$ profiles are presented: CALIOP and SNU-L $R_{\text {app }}$ ( $z_{\text {ref-below) profiles estimated by }}$ choosing $z_{\text {ref }}$ below $(5-6 \mathrm{~km})$ the cirrus layer and CALIOP $R_{\text {app }}\left(z_{\text {ref_above }}\right)$ profile estimated by choosing $z_{\text {ref }}$ above $(12-13 \mathrm{~km})$ the cirrus clouds. We selected 3 different atmospheric scenes with different layer altitudes of cirrus clouds as well as different lidar return signal strengths, although the thickness of cloud layers looks similar.

Figure 3 shows results from daytime observations on 25 November 2006. This is the closest CALIOP footprint location to the SNU-L site among the cases considered in this study (see Fig. 1). Similar cirrus and PBL aerosol layer features are seen at the temporal/spatial coincidence point (vertical white dashed line in Fig. 3a and b). Figure $3 \mathrm{c}$ illustrates the strongest $R_{\text {app }}$ is detected from transmissive cirrus centered around $11.2 \mathrm{~km}$ amsl and that a secondary peak is observed below approximately $1.3 \mathrm{~km}$ a.m.s.l., corresponding to the top of the urban aerosol mixing height in Seoul metropolitan area. Compared to

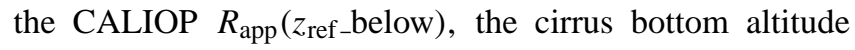
of $R_{\text {app }}\left(z_{\text {ref_above }}\right)$ is slight higher. This is attributable to

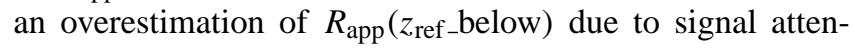
uation by cirrus. A lower signal at $z_{\text {ref }}$ below leads to a stronger $R_{\text {app }}$ (see Eq. 1). The cirrus bottom altitude of $R_{\text {app }}\left(z_{\text {ref_above }}\right)$ is more in agreement with that estimated by CALIPSO science team algorithm for cloud layer identification (see also Figs. 4 and 5). $R_{\text {app }}$ ( $z_{\text {ref-below) of SNU-L }}$ in PBL falls into the uncertainty range of CALIOP-derived $R_{\text {app }}\left(z_{\text {ref }}\right.$ below). The top and base boundaries of the semitransparent cirrus cloud determined from both lidars are in agreement within $0.050 \mathrm{~km}$ and $0.110 \mathrm{~km}$, respectively (Table 2). The thickness of the cirrus layer retrieved from CALIPSO science team level-2 and SNU-L algorithms is $580 \mathrm{~m}$ and $740 \mathrm{~m}$, respectively. The estimated PBL top height from both lidars is also in close agreement: $1.28 \mathrm{~km}$ (CALIOP) and $1.29 \mathrm{~km}$ (SNU-L) (Table 2).
A thicker cirrus cloud, but having lower cirrus signal strength than the case given in Fig. 3, was observed on 21 February 2007 (Fig. 4). This was a night-time CALIOP flight. The ground track is at the farthest distance from the SNU lidar site among the 6 cases shown in this study, but still the CALIOP ground track is located within $10 \mathrm{~km}$ in horizontal distance (Fig. 1). Because the signal-to-noise ratio is better during the night-time (see Sect. 4.4 for further discussion), the differences between $R_{\text {app }}\left(z_{\text {ref }}\right.$ above) and

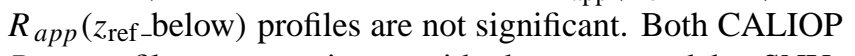
$R_{\text {app }}$ profiles are consistent with that measured by SNUL. The cirrus layer top and bottom altitudes are identified as $10.54 \mathrm{~km}(10.45 \mathrm{~km})$ and $9.64 \mathrm{~km}(9.60 \mathrm{~km})$ by CALIOP (SNU-L) (Table 2). The thickness of the cirrus layer is in good agreement: $0.90 \mathrm{~km}$ from CALIOP and $0.85 \mathrm{~km}$ from SNU-L. Both lidars well detect three distinct aerosol layers (labeled "A1" to "A3") below the cirrus. The aerosol layer thickness from CALIOP and SNU-L (in parenthesis) is $0.75 \mathrm{~km}(0.78 \mathrm{~km})$ for $\mathrm{A} 1,1.04 \mathrm{~km}(1.10 \mathrm{~km})$ for $\mathrm{A} 2$, and $0.42 \mathrm{~km}(0.40 \mathrm{~km})$ for A3. This comparison suggests that the detection of semi-transparent cirrus and underlying multiple aerosol layers during night-time portion of the CALIPSO orbits is reliable.

Figure 5 shows results from observations on 12 January 2007 (daytime ascending node). The altitude of the cirrus is more in agreement with that estimated by CALIPSO science team algorithm for cloud layer identification when $z_{\text {ref }}$

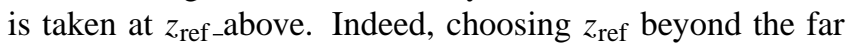
boundary of layer for CALIOP (i.e. $z_{\text {ref_below) causes } R_{\text {app }}}$ to overestimate the true scattering ratio, and thus to increase the cloud thickness. Such an overestimation in the case of $z_{\text {ref-below has nevertheless an advantage, in the fact that }}$ the boundary layer, which is basically attenuated in the case of down-looking CALIOP signal, is more clearly detected. Therefore, choosing $z_{\text {ref }}$ below the cirrus clouds in case of CALIOP signal leads to a loss of information in the detection of the cirrus altitude, whereas increases at the same time the chance of efficiently detecting the boundary layer. As we can see from $R_{\text {app }}\left(z_{\text {ref_below), the estimated PBL top height }}\right.$ from both lidars is in close agreement. The cloud layer (labeled " $\mathrm{C}$ ") top and bottom (in parenthesis) height is identified by CALIOP at $8.06 \mathrm{~km}(7.22 \mathrm{~km})$, and the PBL aerosol layer (labeled "A") top and base (in parenthesis) at $0.78 \mathrm{~km}$ (ground). The ground-based SNU-L shows similar results, except for the PBL top height at $1.26 \mathrm{~km}$ (Table 2). Based on the PBL aerosol mixing heights at Seoul from Fig. 5b, the ground-based SNU-L measurements of aerosol signals from surface to about $1.2-1.3 \mathrm{~km}$ seems correct. Larger CALIOP signal noise during daytime (see Fig. 5c) probably limits the accuracy of the CALIOP algorithm for the PBL top height detection below cirrus clouds.

Overall, all cases presented in Figs. 3, 4 and 5 provide proof that the CALIPSO science team algorithms for the discrimination of cloud and aerosol as well as for the detection of layer top and base altitudes perform well. The top 

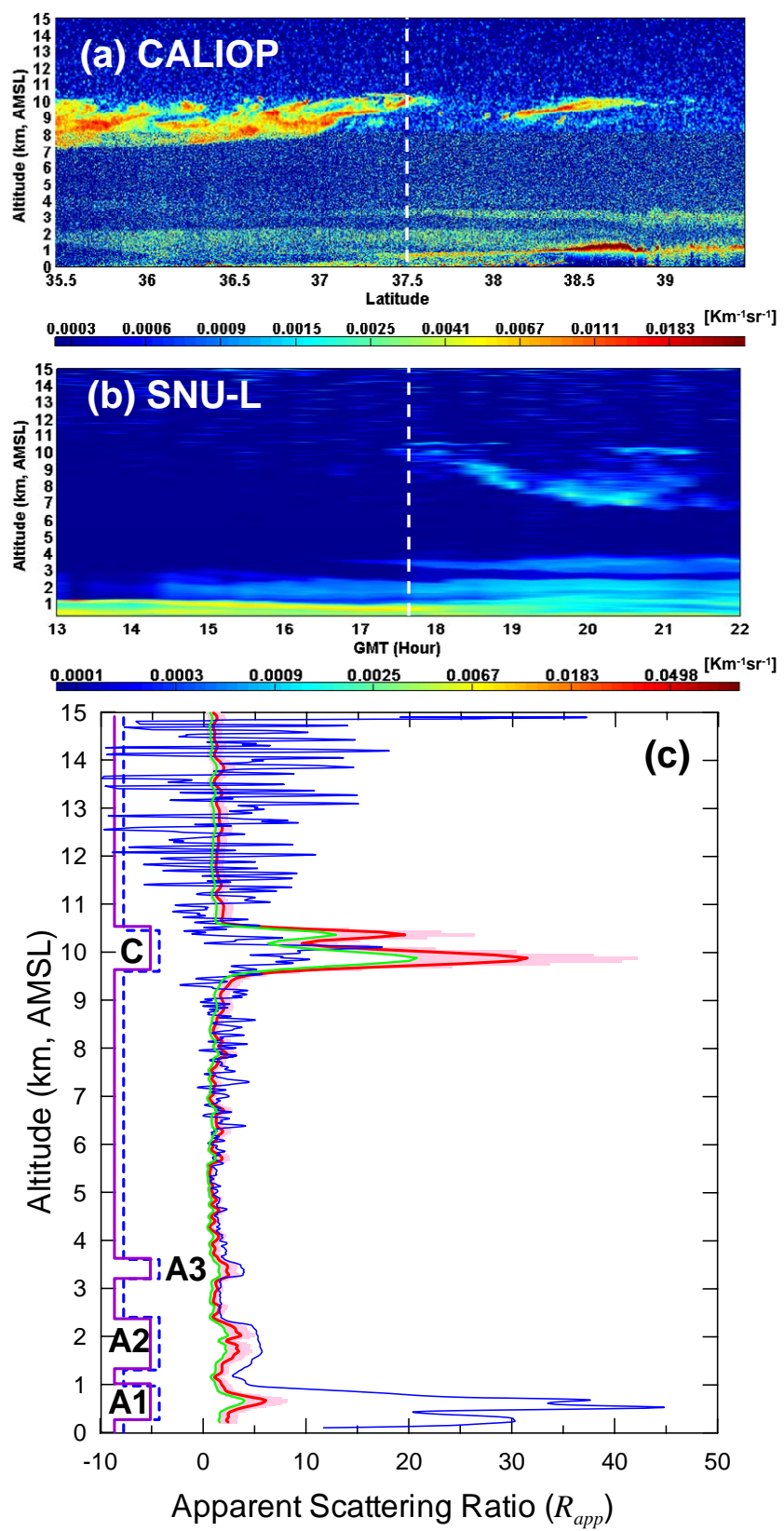

Fig. 4. Same as Fig. 3, on 21 February 2007 (17:41 UTC).

and base heights of cloud and aerosol layers estimated from coincident space-borne CALIOP and ground-based SNU-L measurements are generally in agreement within $0.10 \mathrm{~km}$. However, compared to CALIOP signal during night-time, the noise in daytime CALIOP profiles is more important because of the solar light and may introduce significant errors on the PBL aerosol under cirrus clouds. Complementary discussion on this point is given in Sect. 4.4.

\subsection{Case 3: thick clouds}

Comparisons of vertical profiles of $R_{\text {app }}$ under the condition of an aerosol layer underlying dense clouds in upper and middle troposphere are presented here for 2 night-time CALIOP flights (Table 1). Figure 6 shows CALIOP and SNU-L profiles on 24 September 2006. In Fig. 6a and b, discrepancies between the two lidar signals are found for cloud layer top and base altitudes as well as for the presence of an aerosol layer under the clouds. The $R_{\text {app }}$ profiles (Fig. $6 \mathrm{c}$ and d) reveal strong signal attenuations due to 

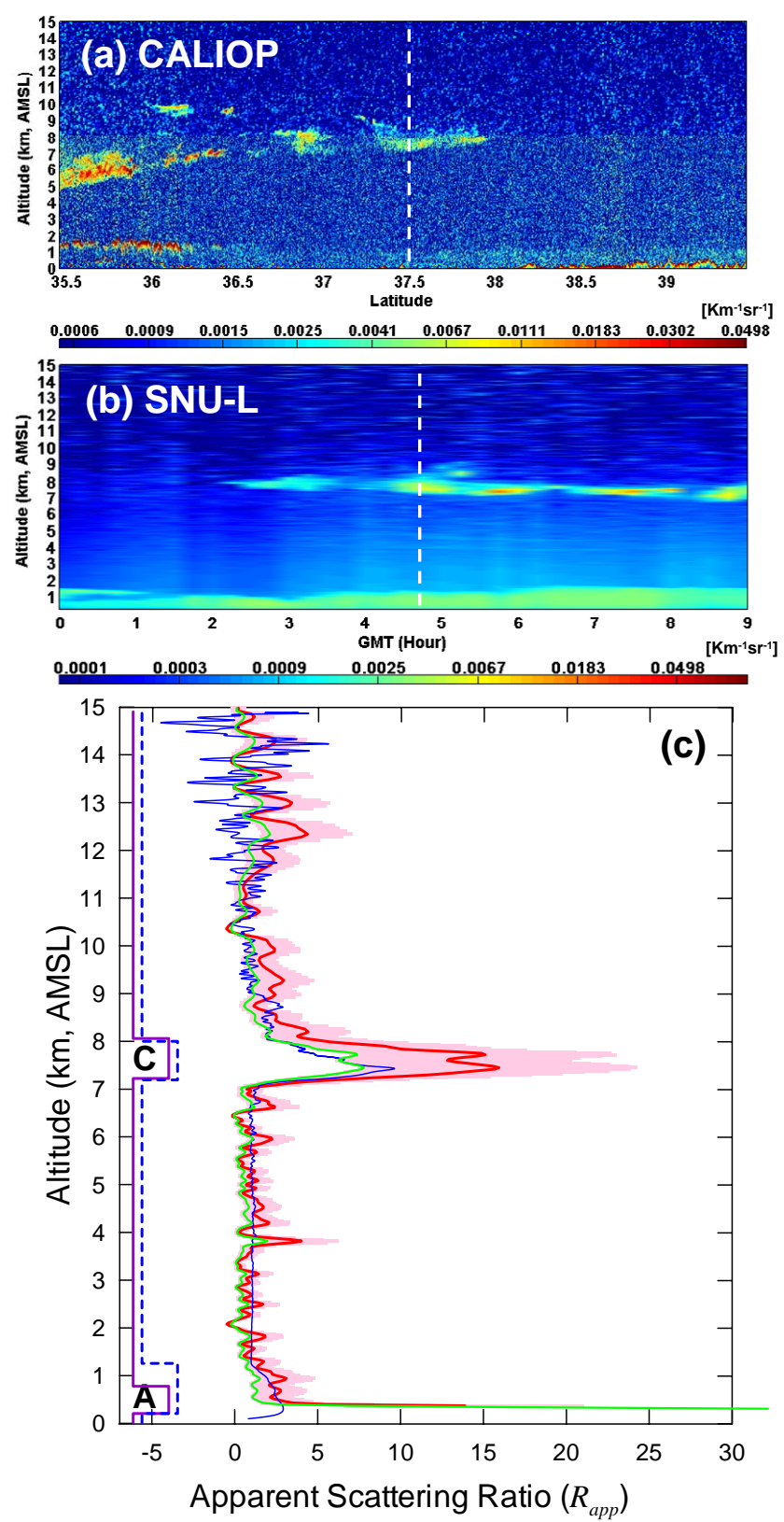

Fig. 5. Same as Fig. 3, on 12 January 2007 (04:50 UTC).

the thick cloud layer. CALIOP-derived $R_{\text {app }}$ identifies a single $5.25-\mathrm{km}$ thick cloud $\left(C_{S}\right)$ between 4.95 and $11.20 \mathrm{~km}$, which in fact looks like a two-layered cloud structure: a thick high-altitude cloud from 6.95 to $11.20 \mathrm{~km}$ and an underlying middle-tropospheric thick cloud (e.g. stratocumulus) from 4.95 to $6.95 \mathrm{~km}$ (Fig. 6c). As we mentioned in Sect. 3.1, it should be noted that CALIOP-derived $R_{\text {app }}$ profile is only estimated by choosing $z_{\text {ref }}$ between 12 and $13 \mathrm{~km}$ ( $\left.z_{\text {ref_above }}\right)$ in this case due to complete signal attenuation below thick cloud layer (see Fig. 6d). The top and base heights of the cloud layer estimated from SNU-L $\left(C_{g}\right)$ are 4.70 and $6.90 \mathrm{~km}$
(Table 2) which indicates that the upper cloud layer is not detected. The peak in $R_{\text {app }}$ as seen by SNU-L is also at a significantly lower height than that seen by CALIOP (Fig. 6c).

The PBL aerosol layer $\left(A_{g}\right)$ observed by SNU-L, as shown enlarged in Fig. 6d, is not visible in CALIOP profile. As mentioned above, this is related to the limits of atmospheric remote sensing by using the lidar techniques. Laser light emitted from the CALIOP (and/or the backscattered light) does not penetrate the whole cloud downward (upward), and inversely, the thick cloud layer blocks the upward (downward) penetration of the laser beam (and/or return signal) 

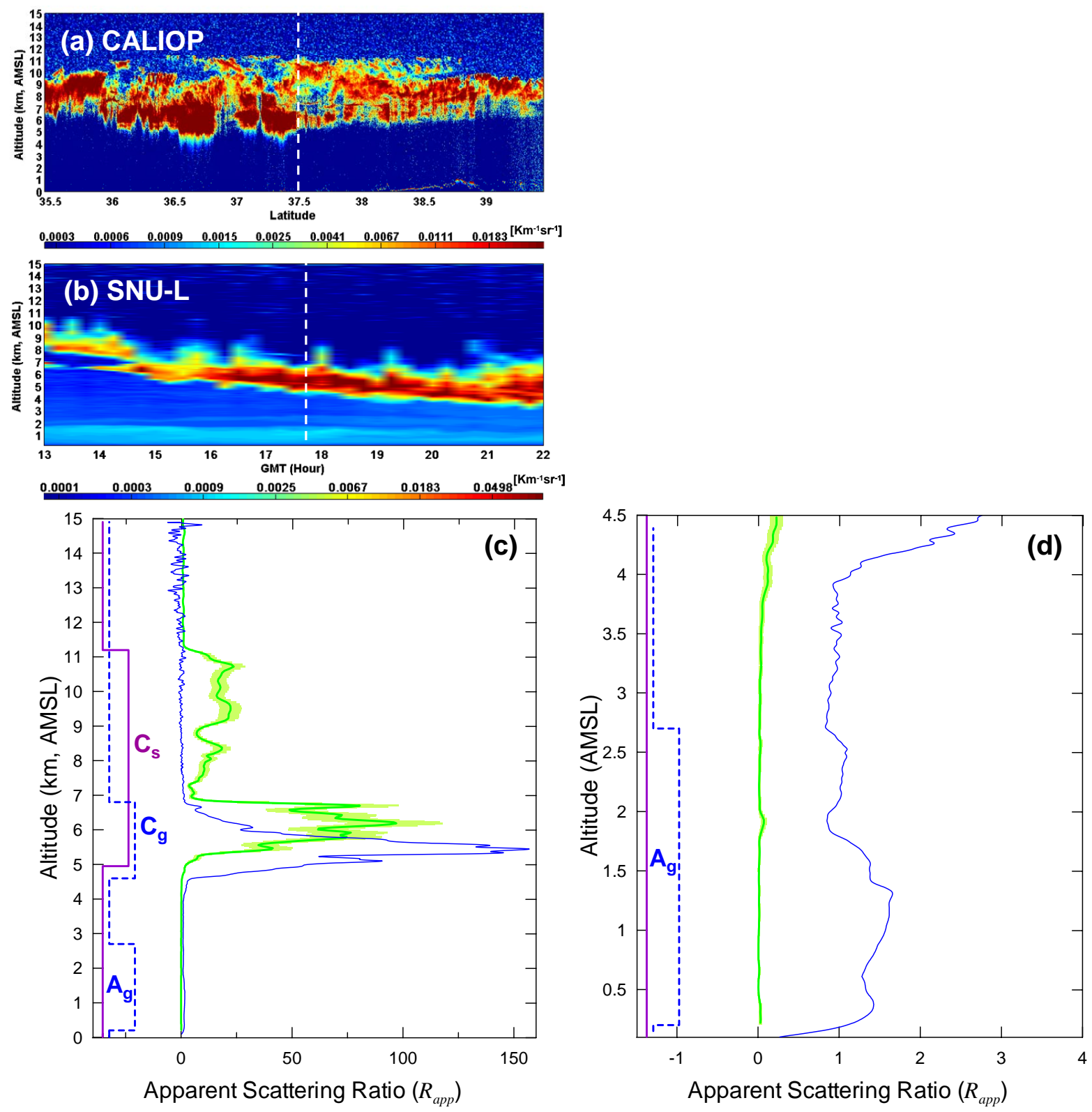

Fig. 6. Same as Fig. 2, except for the presence of middle and high altitude thick cloud over the lower troposphere aerosol layer, on 14

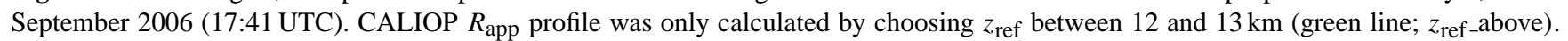
An enlarged figure of vertical profiles below $4.5 \mathrm{~km}$ shown in (c) is given in (d) for better viewing. Subscripts "g" and "s" in (c) and (d) denote the ground-based and space-borne measurements, respectively.

from the ground-based SNU-L (scattering particles). Add to this that spatially and vertically inhomogeneous distributions of clouds at few kilometer horizontal scales are also potential causes of discrepancies in the determination of layer top and bottom heights. To check this point, we plot on Fig. 7 the 18 profiles of CALIOP level-1 data (total attenuated backscatter $\beta_{532}^{\prime}$ which are used for $R_{\text {app }}$ calculation shown in Fig. 6c) closest to the ground-based SNU lidar site on 14 September 2006. The white lines represent CALIOP-derived cloud top $\left[C_{S}\right.$ (top) $]$ and base $\left[C_{S}\right.$ (bottom) $]$ altitudes, as provided by CALIOP level- 2 cloud products at $1 \mathrm{~km}$ horizontal resolution. CALIPSO overpass over the ground-based lidar site corresponds to profiles 9 and 10. Noticeable changes of both middle-tropospheric thick cloud (e.g. weak $\beta_{532}^{\prime}$ from profile 1 to 3 ) and overlaying cirrus cloud (e.g. before and after profile 9) are apparent along the CALIPSO track a few $\mathrm{km}$ apart from the SNU-L site. However, the cloud layer top and bottom heights of the 6 level-2, 1-km horizontal reso- 


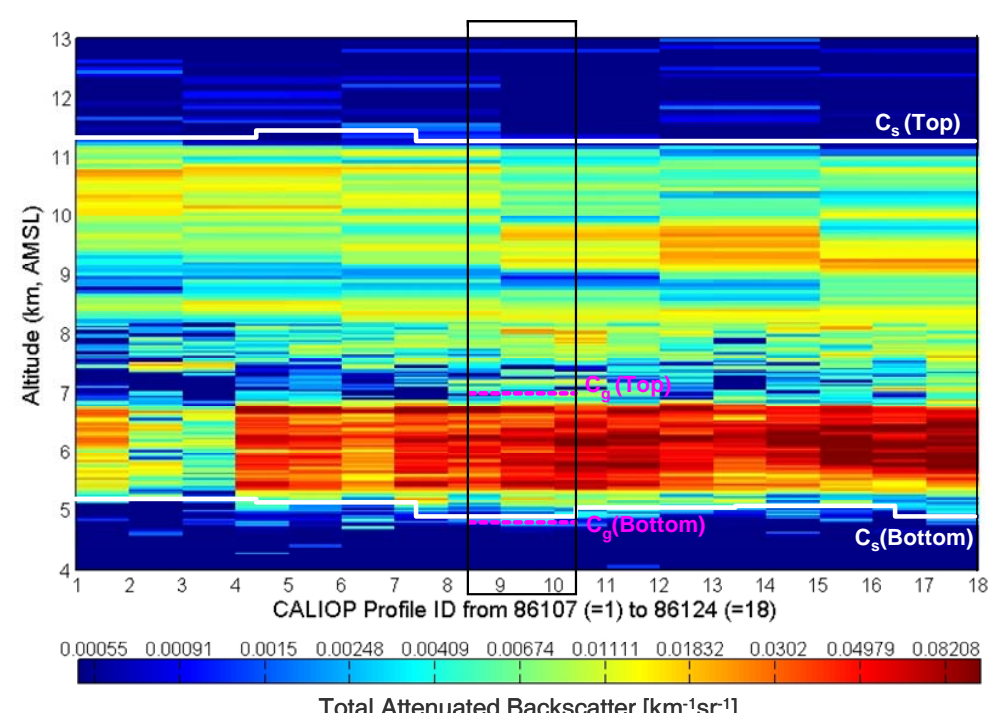

Fig. 7. The 18 profiles of CALIOP-derived total attenuated backscatter at $532 \mathrm{~nm}$ wavelength closest to the ground-based SNU lidar site on 14 September 2006. The horizontal resolution is $0.333 \mathrm{~km}$ below $8.2 \mathrm{~km}$ a.m.s.l. and $1 \mathrm{~km}$ above. The 18 profiles correspond to a distance of $6.0 \mathrm{~km}$. Thin white lines represent CALIOP-derived cloud top $\left[C_{S}\right.$ (top)] and base $\left[C_{S}\right.$ (bottom)] altitudes, provided by CALIOP level 2 cloud products at $1 \mathrm{~km}$ horizontal resolution. The pink dashed lines indicate the cloud top $\left[C_{g}(\right.$ top $\left.)\right]$ and bottom $\left[C_{g}(\right.$ bottom) $]$ heights derived from SNU lidar.

lution profiles varies little, ranging from 11.20 to $11.38 \mathrm{~km}$ and 4.80 to $5.10 \mathrm{~km}$, respectively (Fig. 7). The cloud bottom height determined from CALIOP and SNU-L $C_{g}$ (bottom); pink dashed line in Fig. 7) at the coincidence point are in agreement within $0.1 \mathrm{~km}$. This result confirms that the difference in cloud top height is only due to the ground-based lidar signal attenuation artifact.

Figure 8 is another example of aerosol layer underlying thick clouds on 30 September 2006, night-time. The cloud layer is less thick than in the preceding case (Fig. 6), but shows much stronger lidar return signals. The CALIOPderived $R_{\text {app }}\left(z_{\text {ref }}\right.$ above) shows two thin cloud layers from 8.56 to $8.98 \mathrm{~km}\left(C_{s}^{1}\right)$ and 6.80 to $7.64 \mathrm{~km}\left(C_{s}^{2}\right)$, respectively (Fig. 8c), whereas the ground-based lidar detects a single cloud layer between 4.90 and $6.10 \mathrm{~km}\left(C_{g}^{1}\right)$. Only SNUL shows an aerosol layer $\left(A_{g}\right)$ from surface up to $2.2 \mathrm{~km}$ (Fig. 8d). For this opaque cloud feature that completely attenuated the backscatter signal, the base (top) altitude reported by CALIOP (ground-based lidar) should be considered as an "apparent" rather than true bottom (top) height of the layer. Simultaneous space-borne downward-looking and ground-based upward-looking lidar observations, however, complement each other and can be combined to provide full information on the height and thickness of the 4 aerosol and cloud layers present.

\subsection{Aerosol extinction profiles}

As mentioned in Sect. 3.2, the aerosol backscatterto-extinction ratio (BER) is estimated by using the sunphotometer-derived aerosol optical thickness at $532 \mathrm{~nm}$ $\left(\tau_{a}\right)$ at the SNU site during the CALIOP overpass on 24 October 2006 (case 1). $\tau_{a}=0.125 \pm 0.02$, which is a low value for Seoul area when compared against 1-yr AERONET measurements from March 2001 to February 2002 (e.g. annual mean $\tau_{a}=0.51(440 \mathrm{~nm}), \tau_{a}=0.31(675 \mathrm{~nm})$; October mean $\tau_{a}=0.44$ $\left.(440 \mathrm{~nm}), \tau_{a}=0.26(675 \mathrm{~nm})\right)$. Based on this value, BER is derived as $0.023 \pm 0.004 \mathrm{sr}^{-1}$ (i.e., lidar ratio $\delta=43.2 \pm 6.2 \mathrm{sr}$ ) from CALIOP and as $0.027 \pm 0.006 \mathrm{sr}^{-1}$ (i.e., $\delta=37.4 \pm 7.2 \mathrm{sr}$ ) from the ground-based SNU-L (Table 2). Note that CALIOPderived ABER is considered as BER in this case, because the value of the multiple-scattering factor $(\eta)$ for CALIOP signal is close to 1 for PBL aerosol. These values of the lidar ratio are lower than those reported during Asian dust events (47.1 $\pm 7.0 \mathrm{sr}$ ) and for anthropogenic pollution plumes $(71.1 \pm 8.2 \mathrm{sr})$ in Korea (Noh et al., 2007), but greater than for maritime aerosols (25-30 sr; Cattrall et al., 2005). During this period, the depolarization ratio at $532 \mathrm{~nm}$ derived from the ground-based SNU-L measurements is $6.4 \%$ and the Ångström exponent between 400 and $870 \mathrm{~nm}$ obtained from the sunphotometer is 1.07 , respectively. The air flow came from NE of China and we can assume that the aerosol is made of a small amount of locally emitted pollution and dust-free continental aerosols.

Figure 9 shows aerosol extinction profiles retrieved from CALIOP and SNU-L. The comparison under cloud-free conditions (24 October 2006, Fig. 9 left) illustrates that both lidars show good agreement in the upper part of the PBL $(0.7 \sim 1.2 \mathrm{~km})$ with mean difference of about $0.02 \mathrm{~km}^{-1}$. Compared to the ground-based SNU-L, CALIOP shows 

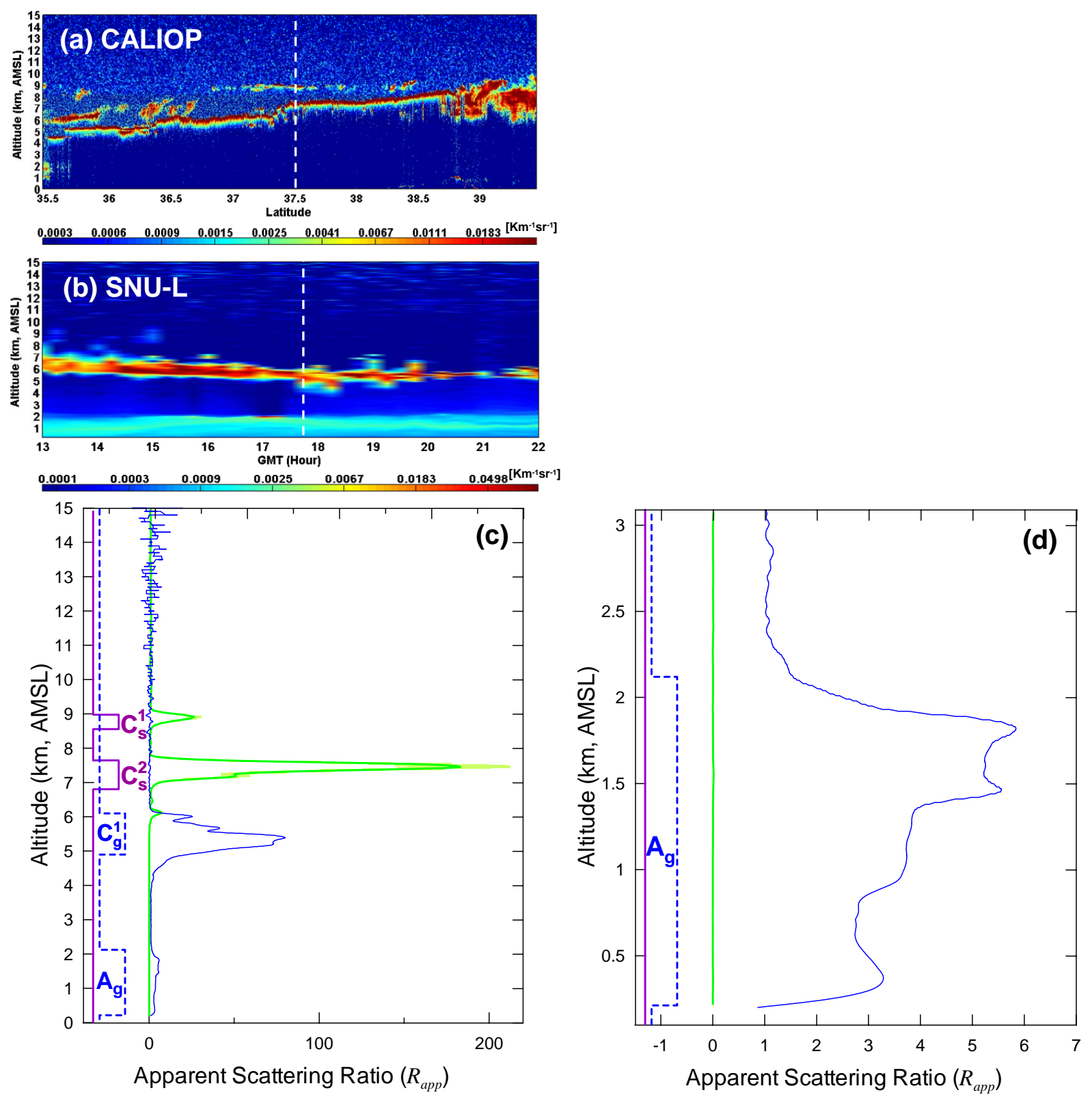

Fig. 8. Same as Fig. 6, on 30 September 2006 (17:41 UTC). An enlarged figure of vertical profiles below $3.1 \mathrm{~km}$ in (c) is given in (d) for better viewing of the boundary layer aerosol.

unexpected peaks of aerosol extinctions above the PBL. This may be due to small signal-to-noise ratio (SNR) during daytime. Under semi-transparent cirrus cloud conditions, the CALIOP-derived aerosol extinction coefficients are about 5 10 times greater than those from SNU-L for daytime observations on 25 November 2006 (Fig. 9, middle left) and 12 January 2007 (middle right). The aerosol extinction profile obtained during the night-time CALIOP flight under semitransparent cirrus cloud conditions (Fig. 9 right) shows good agreement both in aerosol extinction coefficients and in the layer top and bottom structures. This can be explained by the better night-time signal-to-noise ratio (SNR) of CALIOP. In conclusion, it seems that the SNR of CALIOP data obtained during the daytime is not adequate to retrieve the aerosol extinction profile for aerosol layers underlying cirrus clouds. For example, the SNR estimated between 12 and $12.5 \mathrm{~km}$ a.m.s.l. (above cirrus clouds) was about 3.56 on 21 February 2007 (night-time), whereas about 1.79 on 25 November 2006 (daytime). It means that we need to analyze approximately 4 times CALIOP daytime shoots more 


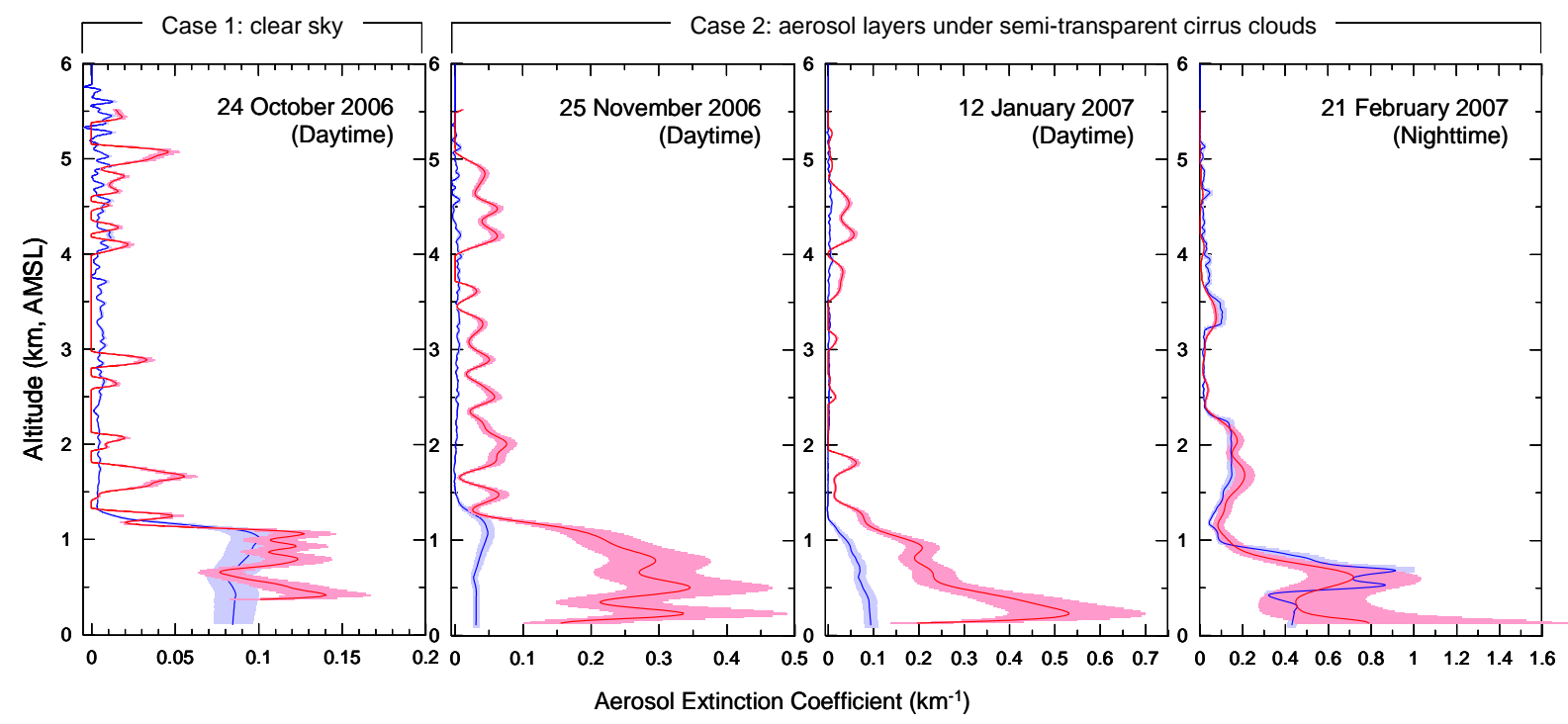

Fig. 9. Comparison of aerosol extinction profiles between CALIOP (red line) and ground-based SNU lidar (blue line) for cloud-free conditions (Case 1, left) and aerosol layers under semi-transparent cirrus clouds (Case 2). The shaded envelopes represent the range of aerosol extinction coefficient originating from the lidar ratio uncertainty.

than night-time shoots to reach the accuracy of the night-time CALIOP profile. That is, 72 CALIOP profiles should be analyzed in daytime case. However, this implies averaging over $\sim 24 \mathrm{~km}$ along the CALIOP tracks and assuming spatial homogeneity of aerosol distributions.

\section{Summary and conclusion}

In this study, we present initial validation results of spaceborne lidar CALIOP profiles using 3 daytime and 3 nighttime coincidental observations from a ground-based lidar at Seoul National University $\left(37.46^{\circ} \mathrm{N}, 126.95^{\circ} \mathrm{E}\right)$. The selected data set covers 3 different typical types of clear and cloudy atmospheric scenes observed between September 2006 and February 2007. Apparent scattering ratios $R_{\text {app }}$ calculated from the two instrument measurements of total attenuated backscattering signals at $532 \mathrm{~nm}$ show similar aerosol and cloud structures both under cloud-free conditions and in case of multi-layered aerosols underlying thin cirrus clouds. The top and base heights of cloud and aerosol layers estimated from simultaneous space-borne CALIOP and ground-based SNU-L measurements are generally in agreement within $0.10 \mathrm{~km}$, particularly during night-time. This result confirms that the CALIPSO science team algorithm for the discrimination of cloud and aerosol as well as for the detection of layer top and base altitudes provides reliable information on the height and thickness of aerosol and cloud layers in such atmospheric conditions. The accuracy of the PBL top height under cirrus clouds appears, however, much more limited during daytime.
We estimate the aerosol backscatter-to-extinction ratio (BER) on a clear day (24 October 2006) by using the sunphotometer-derived aerosol optical thickness $\left(\tau_{a}=0.125\right)$ measured at the SNU site during the CALIOP overpass. We find a value of $0.023 \pm 0.004 \mathrm{sr}^{-1}$ from CALIOP and $0.027 \pm 0.006 \mathrm{sr}^{-1}$ from SNU-L. The comparison of the aerosol extinction profiles from both lidars for the boundary layer aerosol (under cloud-free conditions) is in agreement within about $0.02 \mathrm{~km}^{-1}$. Under semi-transparent cirrus cloud conditions, the aerosol extinction profiles show good agreement for the night-time CALIOP flight (21 February 2007), whereas large discrepancies are found for the daytime flights (25 November 2006 and 12 January 2007) due to small signal-to-noise ratio of the CALIOP data. Daytime CALIOP data request averaging more profiles, meaning a stronger assumption on the scattering layer spatial homogeneity.

In cases of aerosol layers underlying thick tropospheric clouds, comparison results illustrate the limitations of spaceborne downward-looking and ground-based upward-looking lidar measurements due to strong signal attenuations, and imply that only information on the cloud top (bottom) height is reliable from satellite-based CALIOP (ground-based SNUL) observations. However, the complementarity between space-borne and ground-based lidar observations can provide complete vertical structures of aerosols and clouds.

Acknowledgements. S.-W. Kim was supported by the BK21 program in School of Earth and Environmental Sciences (SEES), Seoul National University (SNU), and by the Korea Research Foundation Grant program funded by the Korean Government (MOEHRD, KRF- 2006-214-C00093), and by a grant from the 
French Ministère de l'Education Supérieure et de la Recherche. S.-C. Yoon was supported by the BK21 program in SEES/SNU and by the Climate Environment System Research Center sponsored by the SRC program. The support of CNES (Centre National d'Etudes Spatiales) for S. Berthier is greatly acknowledged. We also thank the CEA (Commissariat à l'Énergie Atomique) and the CNRS (Centre national de la recherche scientifique) for their supports. CALIPSO data were obtained from the NASA Langley Research Center Atmospheric Science Data Center (ASDC) via on-line web orders. We are very grateful to the entire CALIPSO science team for providing CALIOP data and Nobuo Sugimoto (National Institute for Environmental Studies, Japan) for technical support of the SNU lidar. The authors also greatly acknowledge the valuable comments and suggestions from two anonymous reviewers.

Edited by: G. Feingold

\section{References}

Anselmo, T., Clifton, R., Hunt, W., Lee, K.-P., Murray, T., Powell, K., Rodier, S. D., Vaughan, M., Chomette, O., Viollier, M., Hagolle, O., Lifermann, A., Garnier, A., Pelon, J., Currey, J., Pitts, M., and Winker, D.: Cloud-Aerosol LIDAR Infrared Pathfinder Satellite Observations Data Management System, Data Products Catalog, PC-SCI-503, NASA Langley Research Center, Hampton, VA, available at: http://www-calipso. larc.nasa.gov/resources/project_documentation.php, 2005.

Berthier, S., Chazette, P., Couvert, P., Pelon, J., Dulac, F., Thieuleux, F., Moulin, C., and Pain, T.: Desert dust aerosol columnar properties over ocean and continental Africa from Lidar in-Space Technology Experiment (LITE) and Meteosat synergy. J. Geophys. Res., 111, D21202, doi:10.1029/2005JD006999, 2006.

Cattrall, C., Reagan, J., Thome, K., and Dubovik, O.: Variability of aerosol and spectral lidar and backscatter and extinction ratios of key aerosol types derived from selected Aerosol Robotic Network locations, J. Geophys. Res., 110, D10S11, doi:10.1029/2004JD005124, 2005.

Chazette, P.: The monsoon aerosol extinction properties at Goa during INDOEX as measured with lidar, J. Geophys. Res., 108, 4187, doi:10.1029/2002JD002074, 2003.

Hostetler, C. A., Liu, Z., Reagan, J., Vaughan, M., Winker, D., Osborn, M., Hunt, W. H., Powell, K. A., and Trepte, C.: CALIOP Algorithm Theoretical Basis Document - Part 1: Lidar Level I ATBD - Calibration and Level 1 Data Products, PC-SCI-201, NASA Langley Research Center, Hampton, VA, available at: http://www-calipso.larc.nasa.gov/resources/ project_documentation.php, 2005.

Kim, M.-H., Yoon, S.-C., Kim, S.-W., Sugimoto, N., and Shimizu, A.: Comparison of Vertical Extinction Profiles Obtained from 2 Ground-Based Mie-Scattering Lidars at Gosan, Korea during ABC-EAREX2005, 23rd International Laser Radar Conference, Nara, Japan, 449-450, 2006.

Kim, S.-W., Yoon, S.-C., Won, J.-G., and Choi, S.-C.: Groundbased remote sensing measurements of aerosol and ozone in an urban area: A case study of mixing height evolution and its effect on ground-level ozone concentrations, Atmos. Environ., 41(33), 7069-7081, 2007.
Klett, J. D.: Stable analytical inversion solution for processing lidar returns, Appl. Opt., 20(2), 211-220, 1981.

Klett, J. D.: Lidar inversion with variable backscatter/extinction ratios, Appl. Opt., 24(11), 1638-1643, 1985.

Kovacs, T. A., McCormick, M. P., Trepte, C. R., Winker, D. M., Garnier, A., and Pelon, J.: Coordination of quid pro quo groundbased measurements of cloud and aerosol optical properties for validation of the CALIPSO mission, Proc. SPIE Int. Soc. Opt. Eng., 5653, 281-289, 2004.

Kovacs, T. and McCormick, P.: Cloud-Aerosol Lidar and Infrared Pathfinder Satellite Observations (CALIPSO) Quid Pro Quo Validation Plan, available at: http://calipsovalidation.hamptonu.edu/ QPQ_plan062206.htm, 2006.

Kovacs, T.: Comparing MODIS and AERONET aerosol optical depth at varying separation distances to assess ground-based validation strategies for spaceborne lidar, J. Geophys. Res., 111, D24203, doi:10.1029/2006JD007349, 2006.

Liu, Z., Vaughan, M., Winker, D., Hostetler, C. A., Poole, L. R., Hlavka, D. L., Hart, W. D., and McGill, M. J.: Use of probability distribution functions for discriminating between cloud and aerosol in lidar backscatter data, J. Geophys. Res., 109, D15202, doi:10.1029/2004JD004732, 2004.

Liu, Z., Hu, Y., Vaughan, M., Reagan, J., Hostetler, C., Winker, D., Hunt, W., Powell, K., and Trepte, C.: Validation Of Calipso Lidar (CALIOP) Calibration, ILRC 2006, Nara, Japan, 933-936, 2006.

McCormick, M. P., Winker, D. M., Browell, E. V., Coakley, J. A., Gardner, C. S., Hoff, R. M., Kent, G. S., Melfi, S. H., Menzies, R. T., Platt, C. M. R., Randall, D. A., and Reagan, J. A.: Scientific investigations planned for the Lidar In-space Technology Experiment (LITE), B. Am. Meteorol. Soc., 74, 2, 205-214, 1993.

McGill, M. J., Vaughan, M. A., Trepte, C. R., Hart, W. D., Hlavka, D. L., Winker, D. M., and Kuehn, R.: Airborne Validation of Spatial Properties Measured by the CALIPSO Lidar, J. Geophys. Res.,112, D20201, doi:10.1029/2007JD008768, 2007.

Murayama T., Sugimoto, N., Uno, K., Hagiwara, N., Liu, Z., Matsui, I., Sakai, T., Shibata, T., Arao, K., Sohn, B. J., Won, J.-G., and Yoon, S.-C.: Ground-based network observation of Asian dust events of April 1998 in East Asia, J. Geophys. Res., 106(D16), 18 345-18360, 2001.

Noh, Y., Kim. Y., Choi. B., and Murayama, T.: Aerosol lidar ratio characteristics measured by a multi-wavelength Raman lidar system at Anmyeon Island, Korea, Atmos. Res., 86, 76-87, 2007.

Shimizu, A., Sugimoto, N., Matsui, I., Arao, K., Uno, I., Murayama, T., Kagawa, N., Aoki, K., Uchiyama, A., and Yamazaki, A.: Continuous observations of Asian dust and other aerosols by polarization lidar in China and Japan during ACE-Asia, J. Geophys. Res., 109, D19S17, doi:10.1029/2002JD003253, 2004.

Spinhirne, J. D., Palm, S. P., Hart, W. D., Hlavka, D. L., and Welton, E. J.: Cloud and aerosol measurements from GLAS: Overview and initial results, Geophys. Res. Lett., 32, L22S03, doi:10.1029/2005GL023507, 2005.

Sugimoto, N., Matsui, I., Shimizu, A., Uno, I., Asai, K., Endoh, T., and Nakajima, T.: Observation of dust and anthropogenic aerosol plumes in the Northwest Pacific with a two-wavelength polarization lidar on board the research vessel Mirai, Geophys. Res. Lett. 29, 1901, doi:10.1029/2002GL015112, 2002.

Sugimoto, N., Shimizu, A., Matsui, I., Itsushi, U., Arao, K., Chen, Y., Zhao, S., Zhou, J., and Lee, C.-H.: Study of Dust Transport 
Using a Network of Continuously Operated Polarization Lidars, Water Air Soil Poll., 5, 145-157, 2005.

Sugimoto, N., Shimizu, A. Matsui, I., Dong, X., Zhou, J., Bai, X., Zhou, J., Lee, C. H., Yoon, S.-C., Okamoto H., and Uno I.: Network Observations of Asian Dust and Air Pollution Aerosols Using Two-Wavelength Polarization Lidars, 23rd International Laser Radar Conference, Nara, Japan, 851-854, 2006.

Vaughan, M., Young, S., Winker, D., Powell, K., Omar, A., Liu, Z., Hu, Y., and Hostetler, C.: Fully automated analysis of spacebased lidar data: an overview of the CALIPSO retrieval algorithms and data products, Proc. SPIE, 5575, 16-30, 2004.
Vaughan, M., Winker, D., and Powell, K.: CALIOP Algorithm Theoretical Basis Document-Part 2: Feature Detection and Layer Properties Algorithms, PC-SCI-202 Part 2, NASA Langley Research Center, Hampton, VA, available at: http://www-calipso. larc.nasa.gov/resources/project_documentation.php, 2005.

Winker, D. M., Hunt, W. H., and Hostetler, C. A.: Status and Performance of the CALIOP Lidar, Proc. SPIE, 5575, 8-15, 2004.

Winker, D. M., Pelon, J., and McCormick, M. P.: Initial Results from CALIPSO, ILRC 2006, Nara, Japan, 991-994, 2006.

Winker, D. M., Hunt, W. H., and McGill, M. J.: Initial performance assessment of CALIOP, Geophys. Res. Lett., 34, L19803, doi:10.1029/2007GL030135, 2007. 